\title{
Poly(L-glutamic acid) via catalytical hydrogenation for the fabrication of carbon nanotube nanocomposites
}

\author{
Luan Thanh Nguyen ${ }^{a}$,Hai Le Tran ${ }^{b}$, Phong Thanh Mai ${ }^{b}$ Vu Ba Duong ${ }^{c}$,Le-Thu T. Nguyen ${ }^{d *}$ (1), \\ Ha Tran Nguyen ${ }^{a, d^{*}}$ (D) \\ ${ }^{a}$ Vietnam National University-Ho Chi Minh City (VNU-HCM), Ho Chi Minh City University of \\ Technology (HCMUT), National Key Laboratory of Polymer and Composite Materials, Ho Chi Minh \\ City, Vietnam \\ ${ }^{b}$ Vietnam National University-Ho Chi Minh City (VNU-HCM), Ho Chi Minh City University of \\ Technology (HCMUT), Faculty of Chemical Engineering, Ho Chi Minh City, Vietnam. \\ ${ }^{c}$ Ho Chi Minh City University of Education, Faculty of Chemistry, Ho Chi Minh City, Vietnam \\ ${ }^{d}$ Vietnam National University-Ho Chi Minh City (VNU-HCM), Ho Chi Minh City University of \\ Technology (HCMUT), Faculty of Materials Technology, Ho Chi Minh City, Vietnam
}

Received: July 17, 2020; Revised: September 29, 2020; Accepted: November 21, 2020

\begin{abstract}
The synthesis of poly(L-glutamic acid) (PG) was investigated. Reduction of poly(benzyl-L-glutamate) by the palladium/charcoal catalyst proved to be an effective method for obtaining polyglutamic acid pure and particularly exhibiting in the $\alpha$-helix secondary structure. The structure of this synthetic polypeptide was assessed by infrared spectroscopy, gel permeation chromatography, proton nuclear magnetic resonance spectroscopy, temperature-modulated differential scanning calorimetry and wideangle powder X-ray diffraction methods. The $\alpha$-helical PG was, for the first time, combined with multi-walled carbon nanotubes (MWCNTs). The obtained PG was demonstrated to be a promising matrix to disperse MWCNTs, forming MWCNT/PG biocomposites.
\end{abstract}

Keywords: Poly(L-glutamic acid), nanocomposites, multi-walled carbon nanotubes.

\section{Introduction}

The Poly(L-glutamic acid) (PG) is a homo-polyamide that is made of L-glutamic acid units connected by amide bonds. PG is an anionic, water-soluble, non-toxic and biodegradable polyamino acid. Thus, poly(glutamic acid) and its derivatives have attracted plenty of research for a variety of applications in industrial fields, such as medicine, cosmetics, food and water treatments ${ }^{1,2}$. Examples of their applications are thickeners, drug carriers, biological adhesives, hydrogels, heavy metal absorbers, crosslinkers in protein delivery systems, anticancer chemotherapeutic agents, and scaffolds for tissue engineering applications, etc ${ }^{3-6}$. Much research has been done on the bio-synthesis and applications of poly(glutamic acid) prepared by microorganisms ${ }^{3}$. However, the high cost of microbial production of $\mathrm{PG}$, including the costs of substrates and processing, can be a disadvantage ${ }^{7}$. Microbial synthesis of PG also often requires optimizing growth conditions to adjust enantiomeric composition, molecular mass and yield 7 . PG has previously been prepared by reduction of poly(benzyl-L-glutamate) (PBG) by phosphonium iodide ${ }^{8}$. The secondary structures of the synthetic PG prepared via this method and naturally-occuring one have been investigated by infrared spectroscopy, showing the presence of a considerable proportion of the extended $\beta$-sheet form ${ }^{8}$. Alternatively, PG has been chemically prepared via amine-initiated ring-opening polymerization of a $\gamma$-R-

*e-mail: nguyenthilethu@hcmut.edu.vn
L-glutamate N-carboxyanhydride (NCA) monomer, with $\mathrm{R}$ is an acid labile blocking group such as the tert-butyl or piperonyl protecting group ${ }^{9,10}$. However, the ring-opening polymerization of glutamate NCA monomers bearing these substituents often resulted in polyamides with relatively low molecular weights low yields ${ }^{9,11}$. Moreover, although these carboxylic protected polyglutamates can be in the $\alpha$-helix conformation, the PGs resulted after removal of the protected groups have low molecular weights and hence a high propensity for forming $\beta$-sheet aggregates.

In this work, we first studied the synthesis of poly $(\mathrm{L}$ glutamic acid) via palladium(Pd)/charcoal (C)-catalyzed hydrogenation of PBG (Scheme 1), which was later used as a biomaterial matrix for dispersing multi-walled carbon nanotubes. PBG is one of the most well studied polypeptides and its synthesis has been well-established ${ }^{12}$. Amine-initiated ring-opening polymerization of benzyl-L-glutamate NCA easily produced PBG with well-defined secondary structure and high yield ${ }^{13}$. On the other hand, the $\mathrm{Pd} /$ charcoal-catalyzed cleavage of benzyl ester protecting groups releasing carboxylic acid groups has been shown to be an effective pathway for chemical modification of various polymers, such as poly(benzyl acrylate), poly(benzyl malolactonate), poly(benzyl methacrylate) and poly(benzyl malolactonate) $)^{14,15}$. The use of benzyl ester groups for protection of peptide terminals followed by hydrogenation with palladium/carbonhas also been used to fabricate oriented helical peptide layers. 

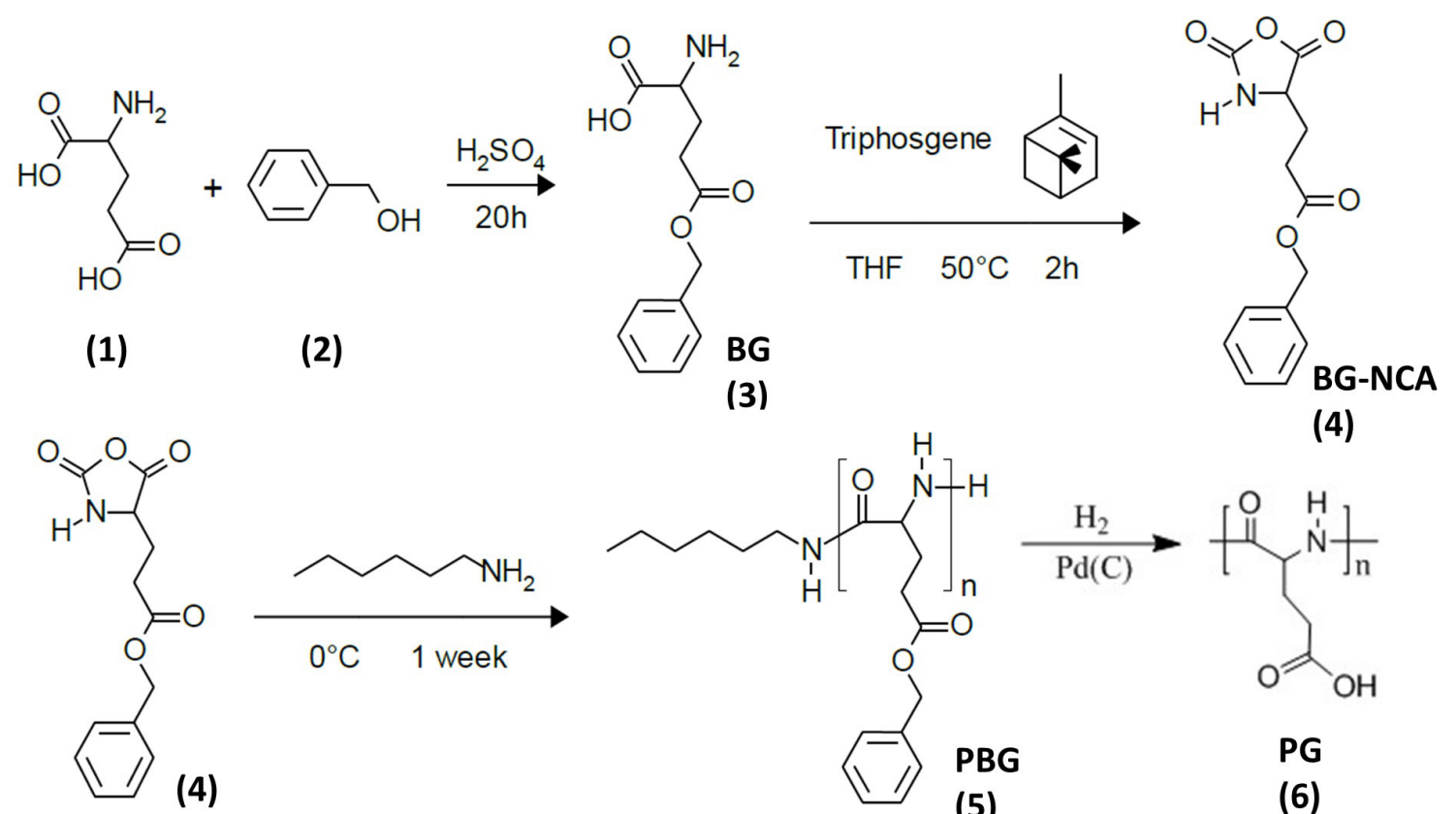

(4)

Scheme 1. Synthesis of PG.

Generally, the hydrogenolysis depends considerably on the progress of the reaction and on the reaction conditions as well as the macromolecular characteristics of the starting polymer. Although low molecular weight compounds such as benzyl glutamate, $N$-carbobenzyloxyglutamate and its anhydride derivative were readily hydrogenated in presence of a palladium charcoal catalyst, hydrogenation of the higher polymers was challenging ${ }^{8}$. Unsuccessful hydrogenation of linear poly(carbobenzyloxylysine) has also been reported by Katchalski et al. ${ }^{16}$.

With the purpose to obtain materials with diverse properties, PG has been subjected to various chemical modifications or combined with other polymer and reinforcement materials ${ }^{17,18}$. For instance, addition of nanoclays to PG complexed with cationic surfactants has recently been investigated in order to improve its mechanical properties ${ }^{19}$. PG has also been combined with $\mathrm{Al}_{2} \mathrm{O}_{3}-\mathrm{SiO}_{2}$ glass for cement preparation.

As an important one-dimensional (1D) material, carbon nanotubes (CNTs) have attracted enormous interest from many industries and research groups due to their remarkable mechanical, electronic, optical and thermal properties ${ }^{20}$. Nanocomposites containing CNTs have potential applications in electronic devices, high-performance composites and biosensors $^{21-23}$. A number of studies have relied on the incorporation of CNTs within biomaterial matrices such as amyloid peptide, poly(benzyl-L-glutamate) or polytyrosine for tissue engineering applications ${ }^{24-27}$. Since covalent modification of CNTs with polypeptides may change the hybridization of the CNT structure and hence lower their mechanical and optoelectronic properties ${ }^{28}$, physical dispersions of CNTs via various methods have been studied ${ }^{29}$.

In the present work, we first synthesized PBG and subsequently investigated the reaction conditions for complete removal of O-benzyl protective side groups via $\mathrm{Pd} / \mathrm{C}$ catalyzed hydrogenation. The reduction of a relatively high molecular weight $\left(\sim 20000 \mathrm{~g} \mathrm{~mol}^{-1}\right)$ PBG via hydrogenation was conducted successfully, producing PG in an $\alpha$-helical secondary structure. It is worth noting that previously reported PG as a block segment extended from a helical poly(glutamate ester) block usually had a high propensity for $\alpha$-helix formation, since the association propensity of the PG block could be inhibited by the helical stability of the poly(glutamate ester) block ${ }^{9}$. However, homo PG may have tendency to form $\beta$-sheet structure depending on the synthesis conditions. To the best of our knowledge, PG has not been combined with CNTs. Thus, the synthesized helical PG was used as the polymer matrix for dispersing multi-walled CNTs, resulting in PG/CNT nanocomposites. The effects of the CNT content on CNT dispersibility and mechanical properties of the nanocomposites were investigated.

\section{Experimental}

\subsection{Materials}

Sulfuric acid (Boomlab, 96\%), diethyl ether (Lab-scan 99.5\%), benzyl alcohol (Acros, 99\%), L-glutamic acid (Aldrich, 99\%), triethylamine (Merck, 99\%), ethanol (Merck, 99.9\%), triphosgene (Acros, 99\%), $\alpha$-pinene (Aldrich 98\%), n-hexane (Lab-scan, 99\%), acetonitrile (Acros, 99\%), tetrahydrofuran (Acros, 99\%), n-hexylamine (Fluka, 98\%), chloroform (Lab-scan, 99.5\%), methanol (Lab-scan, 99.8\%), and palladium on activated charcoal (10\% Pd, Sigma-Aldrich) were purchased and used as received. The solvents used for the synthesis were dried according to standard laboratory procedures prior to use. Baytubes C150P (Bayer Material- 
Science AG, Germany) multi-walled carbon nanotubes (MWCNTs) were used as received.

\subsection{Characterization}

Proton nuclear magnetic resonance ( ${ }^{1} \mathrm{H}$ NMR) spectra were recorded in deuterated solvents with TMS as an internal reference, on a Bruker Avance 300 at $300 \mathrm{MHz}$. Attenuated total reflectance (ATR) FT-IR spectra were collected as the average of 128 scans with a resolution of $4 \mathrm{~cm}^{-1}$ on a FT-IR Tensor 27 spectrometer equipped with a Pike MIRacle ATR accessory with a diamond/ZnSe element. Size exclusion chromatography (SEC) measurements were performed on a Polymer PL-GPC 50 gel permeation chromatograph system equipped with an RI detector, with chloroform as the eluent at a flow rate of $1.0 \mathrm{~mL} / \mathrm{min}$. Molecular weight and molecular weight distribution were calculated with reference to polystyrene standards. Temperature-modulated differential scanning calorimetry (TMDSC) thermograms were recorded using a TA-Instruments T-MDSC 2920 instrument. Nitrogen gas was used as purge gas. Liquid nitrogen was used to cool the system. The samples were studied in standard $40 \mu \mathrm{L}$ aluminium sample pans and at a scan rate of $2.5^{\circ} \mathrm{C} \mathrm{min}^{-1}$. Wide-angle powder X-ray diffraction (WAXD) patterns were recorded at room temperature on a Bruker AXS D8 Avance diffractometer using $\mathrm{Cu} \mathrm{K} \alpha$ radiation $(\mathrm{K}=0.15406 \mathrm{~nm})$, at a scanning rate of $0.05^{\circ} \mathrm{s}^{-1}$. The data were analyzed using DIFRAC plus Evaluation Package (EVA) software. The d-spacings were calculated from peak positions using $\mathrm{Cu}$ KSegoe UI Symbol radiation and Bragg's law. The morphology of the dispersion of MWCNTs in the PG matrix was observed by transmission electron microscopy (TEM, JEM 1400, JEOL, Japan) of $70 \mathrm{~nm}$ thick microtomed layers of the composites. Mechanical properties of dog bone shaped samples were measured with a Tensilon RTC-1210A tensile testing machine, making use of a $1000 \mathrm{~N}$ load cell (according to ASTM D638). At least four specimens were tested for each composition. Scanning electron microscope (SEM) images were obtained on a Field Emission Scanning Electron Microscope, Jeol JMS-6480LV.

\subsection{Synthesis of benzyl-L-glutamate $(B G)$}

To a $1 \mathrm{~L}$ round flask, $60 \mathrm{~mL}$ of diethyl ether was filled in. With continuous stirring, $12 \mathrm{~mL}$ of concentrate sulfuric acid was added dropwise. Then $120 \mathrm{~mL}$ of benzyl alcohol was added and the ether was removed by rotary evaporation. $17.0 \mathrm{~g}$ of L-glutamic acid was added and the mixture was stirred for $20 \mathrm{~h}$ at room temperature. $250 \mathrm{~mL}$ ethanol and $100 \mathrm{~mL}$ triethylamine were added slowly to form white suspension. Then it was crystallized at $5{ }^{\circ} \mathrm{C}$ for $24 \mathrm{~h}$. The raw product was collected by filtration and washed with ethanol. After recrystallization from $800 \mathrm{~mL}$ water at $80^{\circ} \mathrm{C}$, the white product was dried under vacuum at $50^{\circ} \mathrm{C}$ overnight and was stored at $-18{ }^{\circ} \mathrm{C}$. Yield: $70 \%$.

\subsection{Synthesis of benzyl L-glutamate-NCA (BG-NCA)}

$11.85 \mathrm{~g}$ of BG $(0.05 \mathrm{~mol})$ was dissolved in $100 \mathrm{~mL}$ of dry THF. $19.0 \mathrm{~mL}$ of $\alpha$-pinene $(0.12 \mathrm{~mol}, 1.2 \mathrm{eq}$.) and $5.94 \mathrm{~g}$ of triphosgene ( $0.02 \mathrm{~mol}, 0.4 \mathrm{eq}$.) were added respectively. The reaction was carried out at $50{ }^{\circ} \mathrm{C}$ for at least 2 hours until the reaction solution became clear. After that, it was moved to a Schlenk tube under nitrogen atmosphere. Inside the tube, the raw BG-NCA was filtered and precipitated in $300 \mathrm{~mL}$ n-hexane. Then it was collected by filtration and dried out by vacuum. The raw NCA was dissolved in THF and precipitated in $\mathrm{n}$-hexane twice. The white powder product was stored under nitrogen atmosphere at $-18{ }^{\circ} \mathrm{C}$. Yield: $80 \%$.

\subsection{Synthesis of poly(benzyl-L-glutamate) (PBG)}

Firstly, BG-NCA was dissolved in dry chloroform to form $5 \% \mathrm{w} / \mathrm{v}$ solution. At $0{ }^{\circ} \mathrm{C}$, n-hexylamine initiator was injected and the reaction mixture was stirred for 1 week. Then solution was precipitated into methanol, filtrated and dried under vacuum at $50{ }^{\circ} \mathrm{C}$ overnight, yielding a white product. Yield: 95\%.

\subsection{Synthesis of poly(L-glutamic acid) (PG)}

PG was obtained by hydrogenolysis of PBG. Typically, a flask was loaded with a solution containing PBG dissolved in a mixture of tetrahydrofuran-methanol $(4: 1 \mathrm{v} / \mathrm{v})$ and with the $\mathrm{Pd} / \mathrm{C}$ catalyst (5 or $10 \mathrm{wt} \%$ with respect to $\mathrm{PBG)}$ ). The flask was then connected to a graduated hydrogenation apparatus maintained at constant pressure and temperature. After the reaction, the catalyst was removed by centrifugation and filtration, and the resulting polymer was recovered as a solid powder via precipitation into methanol.

\subsection{Preparation of $M W C N T / P G$ composites}

MWCNT/PG nanocomposites containing different CNT contents $(0.5,0.75,1.0,1.5$ and $2 \mathrm{wt} \%)$ and with thicknesses of $2 \mathrm{~mm}$ were prepared. MWCNTs were dispersed in chloroform and the mixture was sonicated at $35^{\circ} \mathrm{C}$ for $60 \mathrm{~min}$ in a bath sonicator (Cole-Parmer, model 08891-16). Then, PG was added and the mixture was subjected to continuous simultaneous mechanical stirring and ultrasonication at $35^{\circ} \mathrm{C}$ for $120 \mathrm{~min}$, followed by solvent evaporation. The composites were dried in the form of thin sheets.

\section{Results and Discussion}

The synthetic route to PG is described in Scheme 1.

\subsection{Synthesis of monomers}

Benzyl-L-glutamate (BG) was first synthesized by Fischer esterification of L-glutamic acid and benzyl alcohol. The method of BG-NCA synthesis was modified from a patent of Cornille et al..$^{30}$ Triphosgene was used to replace phosgene, as it is safer and easier to handle ${ }^{31}$. The monomers were obtained with reasonable yields and high purities, as determined by ${ }^{1} \mathrm{H}$ NMR results. The ${ }^{1} \mathrm{H}$ NMR spectra of the BG and BG-NCA monomers with all characteristic peaks well assigned, are shown in Figure 1. The structure of BG is indicated by the peak related to amino protons at $7.89 \mathrm{ppm}$, aromatic peaks at $7.31 \mathrm{ppm}$, the peak corresponding to oxymethylene protons at $5.09 \mathrm{ppm}$, and the $\mathrm{CH}$ and $\mathrm{CH}_{2}$ peaks at 4.11, 2.75 and $2.19 \mathrm{ppm}$ (Figure 1A). The formation of the BG-NCA monomer is confirmed by the disappearance of the amino peak at $7.89 \mathrm{ppm}$, the appearance of a new peak at $6.70 \mathrm{ppm}$ attributed to the ring amide proton and the shift of the methine peak from 4.11 to $4.40 \mathrm{ppm}$. 


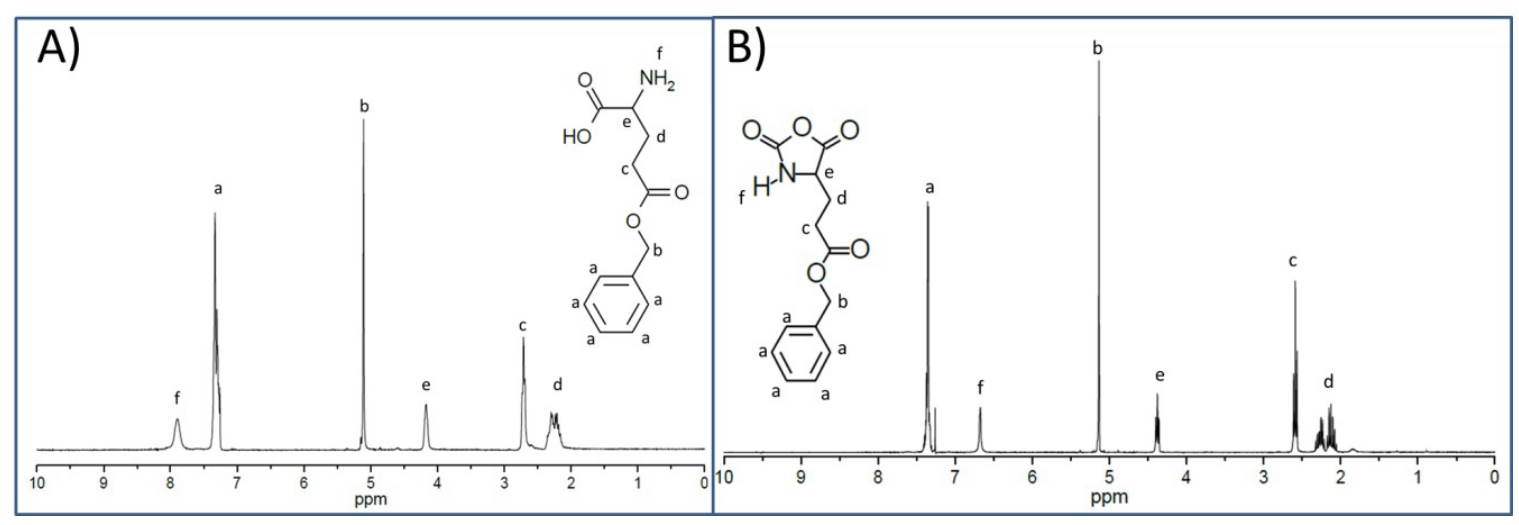

Figure 1. ${ }^{1} \mathrm{HNMR}$ spectra of BG (A) and BG-NCA (B).

\subsection{Synthesis of $P B G$}

Then, PBG was synthesized through ring-opening polymerization of BG-NCA using the polymerization conditions according to a previously reported living NCA polymerization procedure ${ }^{9,32}$. Unreacted monomer was eliminated via polymer precipitation. PBG was obtained at a good yield of $95 \%$. The feeding molar ratio between BG-NCA and the amine initiator was 100/1, and thus the targeted number average molecular weight was $\sim 22000 \mathrm{~g}$ $\mathrm{mol}^{-1}$. The obtained PBG had a GPC-recorded number average molecular weight value of $20200 \mathrm{~g} \mathrm{~mol}^{-1}$ and relatively low polydispersity index (Đ) values of 1.18. The ${ }^{1} \mathrm{H}$ NMR spectrum of $\mathrm{PBG}$ in $\mathrm{CDCl}_{3}$ is presented in Figure 2A, with all characteristic peaks well assigned, including aromatic peaks at $7.27 \mathrm{ppm}$, oxy-methylene peak at $5.10 \mathrm{ppm}$, peak related to the backbone methine proton at $3.98 \mathrm{ppm}$ and the side group methylene protons in the range of $2.70-1.89 \mathrm{ppm}$. Due to the tendency for polymer chain aggregation as a result of strong amide-amide hydrogen bonding, the signal attributed to the amide proton at $8.2 \mathrm{ppm}$ was not clearly visible. Hence, addition of deuterated trifluoroacetic acid (TFA-d) into the measuring solvent resulted in breaking of hydrogen bonds. As shown in Figure 2B, the signal at $8.2 \mathrm{ppm}$ was clearly visible and the other signals were better resolved.

The Fourier transform-infrared (FT-IR) spectrum of PBG shows characteristic absorption bands of a polyamide structure, including the bands at $1728,1650,1546 \mathrm{~cm}^{-1}$ assigned to the ester $\mathrm{C}=\mathrm{O}$ stretch, amide $\mathrm{I}$ and amide II vibrations, respectively (Figure 3A). The bands at 3060-3030 and $750 \mathrm{~cm}^{-1}$ are characteristic of the benzyl C-H stretching and deformation vibrations, respectively.

\subsection{Synthesis of PBLA via hydrogenation of $P B G$}

The synthesis of PG via palladium(Pd)/charcoal (C)catalyzed hydrogenation of $\mathrm{PBG}$ was further investigated. The reduction of PBG in the presence of $5 \mathrm{wt} \%$ of the $\mathrm{Pd} / \mathrm{C}$ catalyst (with respect to the polymer) was first performed at room temperature $\left(\mathrm{T}_{\text {room }}=28{ }^{\circ} \mathrm{C}\right)$ for 1 day. The FT-IR spectrum of the product after removal of the charcoal catalyst and recovery by precipitation showed a decrease in the intensity of the band at $1728 \mathrm{~cm}^{-1}$ related to the ester $\mathrm{C}=\mathrm{O}$ stretch vibration, accompanied by the appearance of

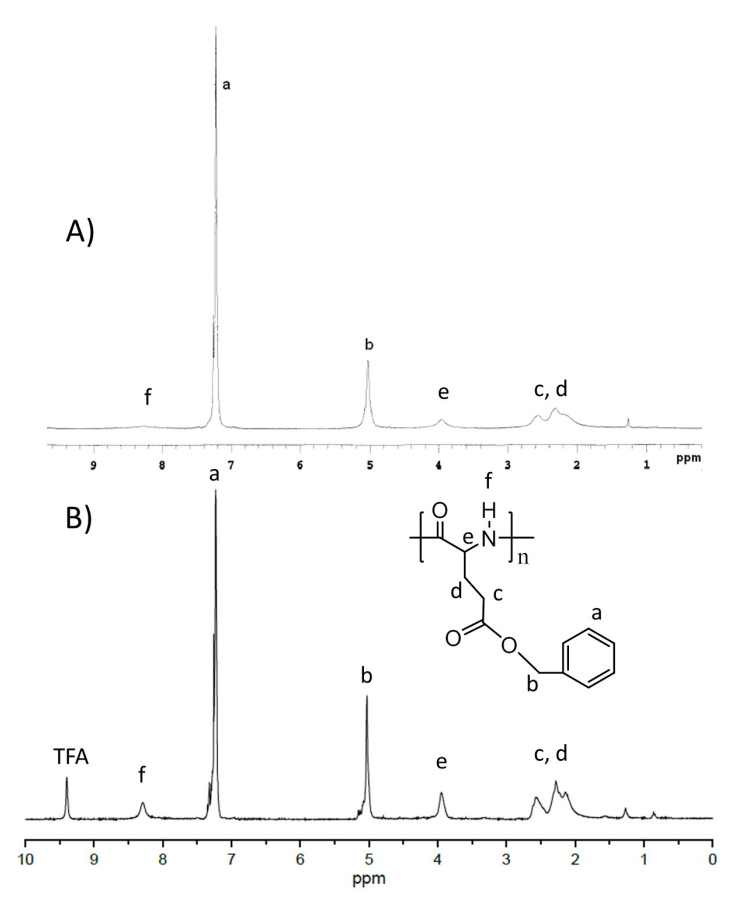

Figure 2. ${ }^{1} \mathrm{H}$ NMR spectrum of $\mathrm{PBG}$ in $\mathrm{CDCl}_{3}(\mathrm{~A})$ and in a mixture of $\mathrm{CDCl}_{3}$ and trifluoroacetic acid-d (TFA-d) $(10 / 1, \mathrm{v} / \mathrm{v})(\mathrm{B})$.

the signal at $1712 \mathrm{~cm}^{-1}$ attributed to the carboxylic acid $\mathrm{C}=\mathrm{O}$ stretch vibration (Figure 4). The incomplete disappearance of both the signal at 1728 and that of the benzyl C-H vibration at $750 \mathrm{~cm}^{-1}$ suggests that the pendant benzyl groups were cleaved partially.

The effect of the hydrogenolysis conditions on the cleaving efficiency of the benzyl ester groups was further assessed by following the FT-IR absorption bands at 1728 and $1712 \mathrm{~cm}^{-1}$. The results are presented in Figure 5. A higher intensity ratio between the band at 1712 and $1728 \mathrm{~cm}^{-1}$ indicates a higher conversion of the benzyl ester to carboxylic group. It was shown that increasing all these factors, i.e. the catalyst content, temperature and pressure was necessary to enhance the reaction conversion. Up to $10 \mathrm{wt} \%$ of $\mathrm{Pd} / \mathrm{C}, 50^{\circ} \mathrm{C}$ and 60 bar, most of the benzyl ester groups were converted to 
carboxylic acid groups after 1 day (curve 5, Figure 4). To obtain a full conversion, the pressure was further increased to 90 bar $\left(10 \mathrm{wt} \%\right.$ of $\mathrm{Pd} / \mathrm{C}, 50^{\circ} \mathrm{C}, 1$ day $)$. The FT-IR spectrum of the corresponding product is shown in Figure 5 (curve 6) and Figure $3 \mathrm{~B}$, in a comparison with that of PBG. Total

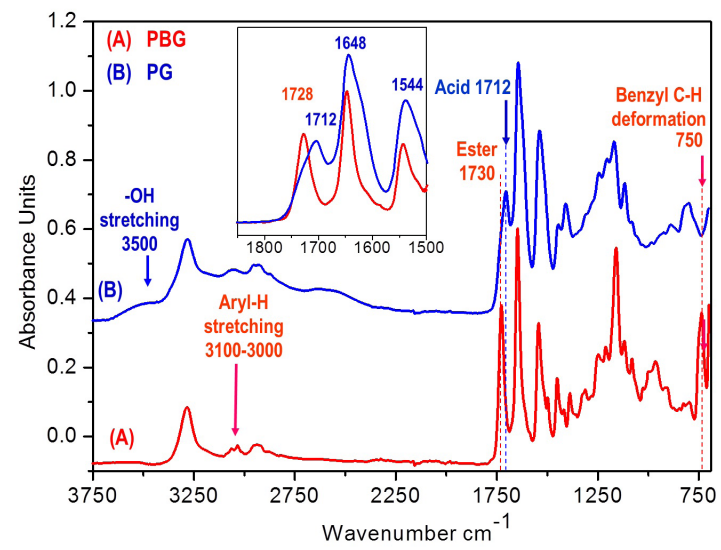

Figure 3. FT-IR spectra of PBG (A) and PG (obtained at condition: $10 \mathrm{wt} \%$ of $\mathrm{Pd} / \mathrm{C}, 50{ }^{\circ} \mathrm{C}, 90$ bar, 1 day) (B). Inset: an overlay of the two spectra in the region of $1850-1500 \mathrm{~cm}^{-1}$ for a comparison.

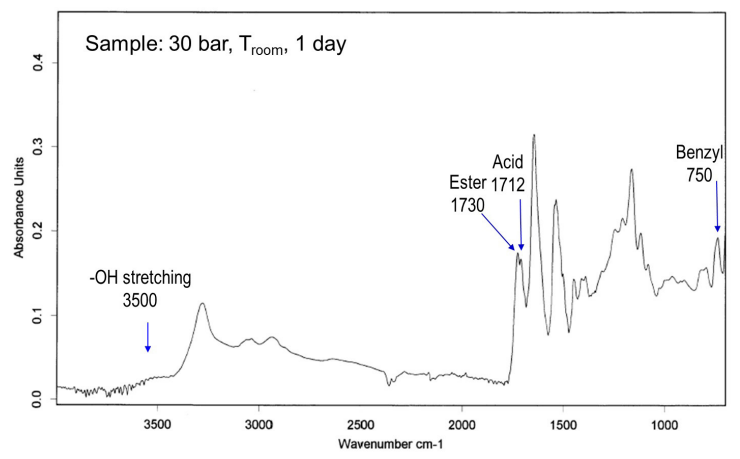

Figure 4. FT-IR spectrum of the product after hydrogenation of PBG with $5 \mathrm{wt} \%$ of the $\mathrm{Pd} / \mathrm{C}$ catalyst at 30 bar, room temperature for 1 day.

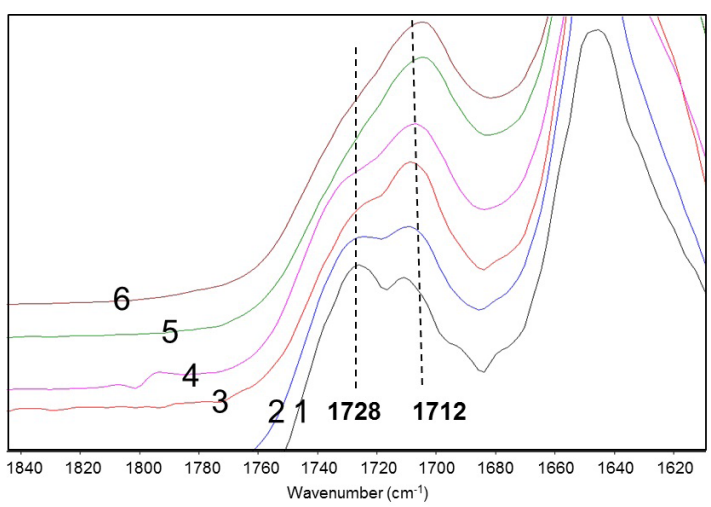

Figure 5. A comparison of the FT-IR spectra in the range of 1830$1600 \mathrm{~cm}^{-1}$ of the products after hydrogenolysis of PBG at different conditions: (1) $5 \mathrm{wt} \%$ of $\mathrm{Pd} / \mathrm{C}, 30 \mathrm{bar}, \mathrm{T}_{\text {room }}, 1$ day; (2) $10 \mathrm{wt} \%$ of $\mathrm{Pd} / \mathrm{C}, \mathrm{T}_{\text {room }}, 30 \mathrm{bar}, 1$ day; (3) $10 \mathrm{wt} \%$ of $\mathrm{Pd} / \mathrm{C}, 50^{\circ} \mathrm{C}, 30 \mathrm{bar}, 1$ day; (4) $10 \mathrm{wt} \%$ of $\mathrm{Pd} / \mathrm{C}, 50{ }^{\circ} \mathrm{C}, 30 \mathrm{bar}, 4$ days; (5) $10 \mathrm{wt} \%$ of $\mathrm{Pd} / \mathrm{C}$, $50{ }^{\circ} \mathrm{C}, 60$ bar, 1 day; (6): $10 \mathrm{wt} \%$ of $\mathrm{Pd} / \mathrm{C}, 50{ }^{\circ} \mathrm{C}, 90$ bar, 1 day. cleavage of the benzyl ester groups was confirmed by the disappearance of the absorption band at $1728 \mathrm{~cm}^{-1}$ related to the ester group and the benzyl vibrational band at $750 \mathrm{~cm}^{-1}$.

These results were in good agreement with the ${ }^{1} \mathrm{H}$ NMR result. As shown in Figure 6, the hydrolysis of the benzyl ester groups is indicated by the decrease in the intensities of the signals corresponding to the benzyl methylene and aromatic protons at 5.10 and $7.27 \mathrm{ppm}$, respectively. The disappearance of these signals suggests total cleavage of the benzyl ester moieties (Figure 6C). The full ${ }^{1} \mathrm{H}$ NMR spectrum of the obtained PG with well-assigned peaks is presented in Figure 7. In purely TFA-d, the hydrogen bonds are dissociated. Hence, the signal of amide proton is wellresolved and appears at $~ 3.9 \mathrm{ppm}$. Compared with the ${ }^{1} \mathrm{H}$ NMR spectrum of $\mathrm{PBG}$, in addition to the disappearance of the benzyl methylene and aromatic protons peaks, that of PG shows shofts of the methine peak to $4.72 \mathrm{ppm}$ and of the amide peak to $3.82 \mathrm{ppm}$.

\subsection{Characterization of $P G$}

The secondary structure of the obtained PG can be indicated by the IR absorption positions of the amide I and amide II characteristic of polyglutamates ${ }^{33}$. Polypeptides in an hydrogen-bonded conformation can exhibit in either an $\alpha$-helical or $\beta$-sheet structures. The $\alpha$-helical structure of polyglutamates shows characteristic IR absorption amide I and II bands at around 1650 and $1545 \mathrm{~cm}^{-1}$ respectively, while the $\beta$-sheet structure is indicated by those at around 1625 and $1525 \mathrm{~cm}^{-133}$. As shown in Figure 3B, the obtained PG shows IR amide bands at 1648 and $1544 \mathrm{~cm}^{-1}$, indicating that the polymer had an $\alpha$-helical conformation.

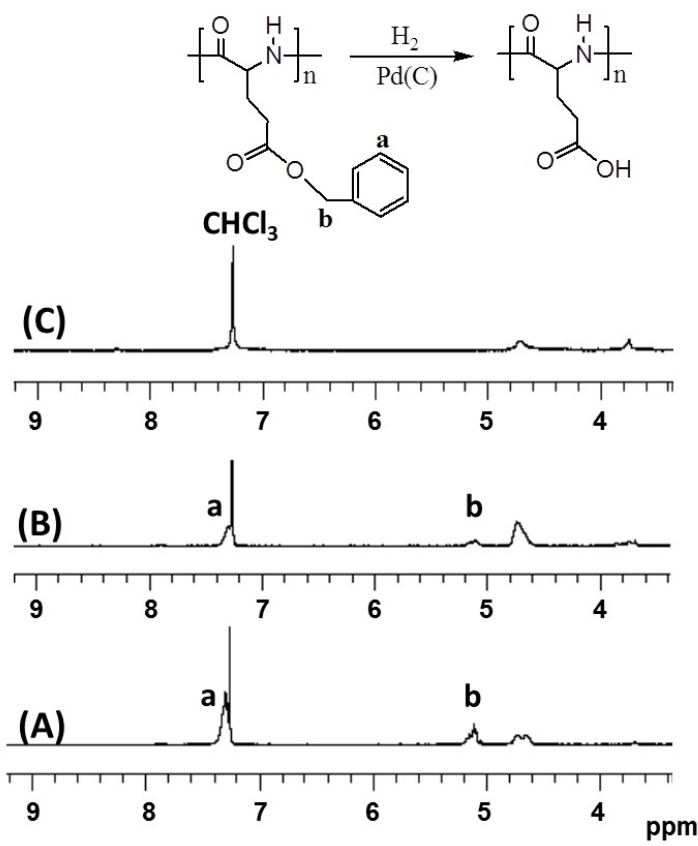

Figure 6. A comparison of the ${ }^{1} \mathrm{H}$ NMR spectra (in a mixture of $\mathrm{CDCl}_{3}$ and TFA-d, 10/1 v/v) in the range of 9.2-3.5 ppm of the products after hydrogenolysis of PBG at different conditions: (A) $5 \mathrm{wt} \%$ of $\mathrm{Pd} / \mathrm{C}, 30 \mathrm{bar}, \mathrm{T}_{\text {room }}, 1$ day; (B) $10 \mathrm{wt} \%$ of $\mathrm{Pd} / \mathrm{C}$, Troom, 30 bar, 1 day; (C): $10 \mathrm{wt} \%$ of $\mathrm{Pd} / \mathrm{C}, 50{ }^{\circ} \mathrm{C}, 90$ bar, 1 day. 
It should be noted that when applying another previously reported method to synthesize PG homopolymer such as reduction of $\mathrm{PBG}$ with phosphonium iodide in acetic acid ${ }^{8}$, we found that the recovered $P G$ after purification and

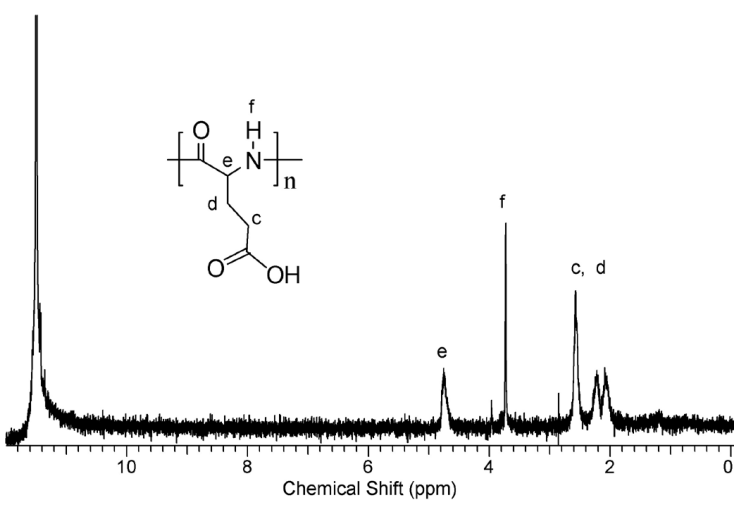

Figure 7. $1 \mathrm{H}$ NMR spectrum (in TFA-d) of PLGA obtained by hydrogenolysis of PBG at $10 \mathrm{wt} \%$ of $\mathrm{Pd} / \mathrm{C}, 50 \mathrm{oC}, 90 \mathrm{bar}$, for 1 day.

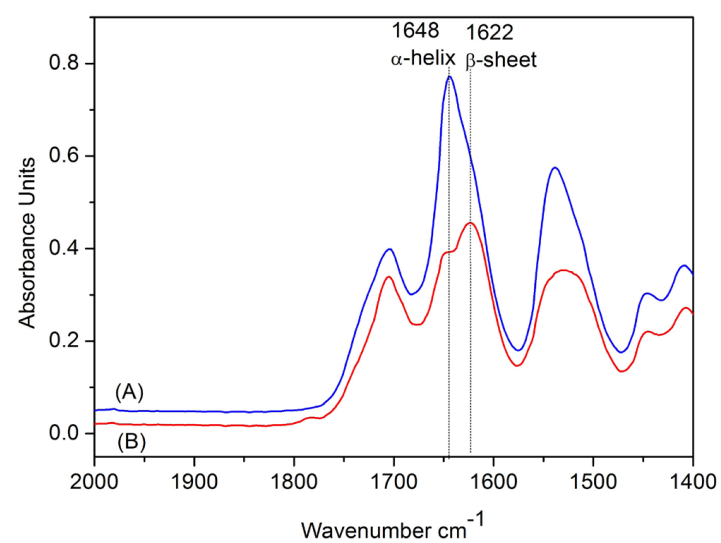

Figure 8. A comparison of the FT-IR spectra of PG obtained via two methods: (A) Pd/C catalyzed hydrogenolysis of PBG; (B): reduction of PBG with phosphonium iodide in acetic acid.

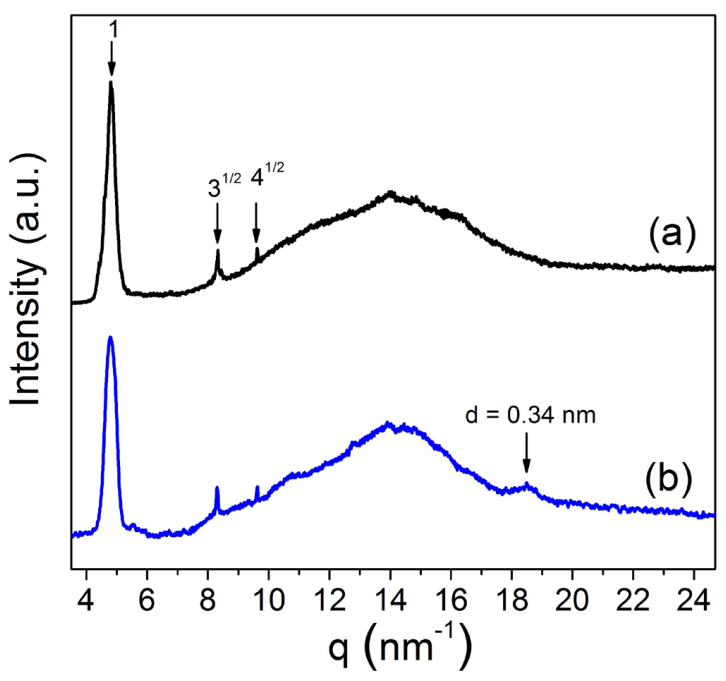

Figure 9. XRD pattern of (a) PG and (b) PG/MWCNT composite. precipitation was mostly transformed to the $\beta$-sheet secondary structure, which was insoluble in common solvents such as chloroform (Figure 8). However, as discussed above, with the $\mathrm{Pd} / \mathrm{C}$ catalyzed hydrogenation method, $\mathrm{PG}$ was obtained in dominated $\alpha$-helical conformation. This is an advantage, as the helical secondary structure is generally favorable because of the good solubility of the polymer in this conformation as well as the intriguing features that could arise from the helix macrodipole with interesting effects on charge transfer and charge transport ${ }^{34,35}$.

The secondary structure of the synthesized PG in the solid state was further determined using wide angle X-ray diffraction (WAXD) experiments. In the WAXD pattern of PBG (Figure 9), the reflection at $\mathrm{q} \sim 3.5 \mathrm{~nm}^{-1}$ characteristic of the $\beta$-sheet lamellar spacing was not found ${ }^{36-38}$. In addition to a broad halo at momentum transfer $\mathrm{q}$ from 8 to $20 \mathrm{~nm}^{-1}$ attributed to the amorphous phase, the primary reflection at $\mathrm{q}=4.81 \mathrm{~nm}^{-1}$ with a d-spacing of $1.31 \mathrm{~nm}$ was observed, reflecting the existence of hexagonally packed cylinders composed of $\alpha$-helix structures. This $\mathrm{d}$-spacing is slightly lower than the distances found in the hexagonal phase of $\alpha$-helical PBG $(1.35-1.40 \mathrm{~nm})^{36-38}$.

The scanning electron microscopy (SEM) micrograph of a film of PG cast is shown in Figure 10, showing a sheaf structure, with the morphology composed of anisotropic rodlike regions typically arising from the $\alpha$-helical conformation ${ }^{39,40}$.

Thermal behavior of the synthesized PG was investigated by temperature-modulated differential scanning calorimetry (TMDSC). The principles employed this technique are described elsewhere ${ }^{41}$. In general, the sample is subjected to a complex heating program involving a sinusoidal temperature modulation overlaid on an underlying linear heating ramp of the DSC. Fourier-transform analysis is applied to separate the total heat flow signal, which is identical to that of conventional DSC, into two componential signals: the reversible (rev.) heat flow which is related to molecular motions, and the nonreversible (nonrev.) heat flow which is caused by a kinetically driven process such as melting, crystallization or a chemical reaction. As shown in Figure 11, The TMDSC thermogram of PG displays a sharp endothermic peak with the top of the peak at $220^{\circ} \mathrm{C}$ in the

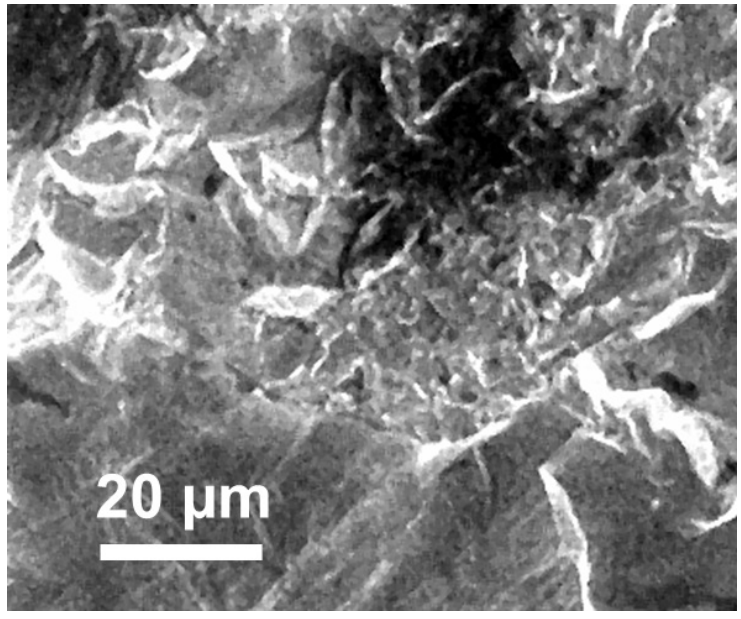

Figure 10. SEM micrograph showing the surface structure of PG. 


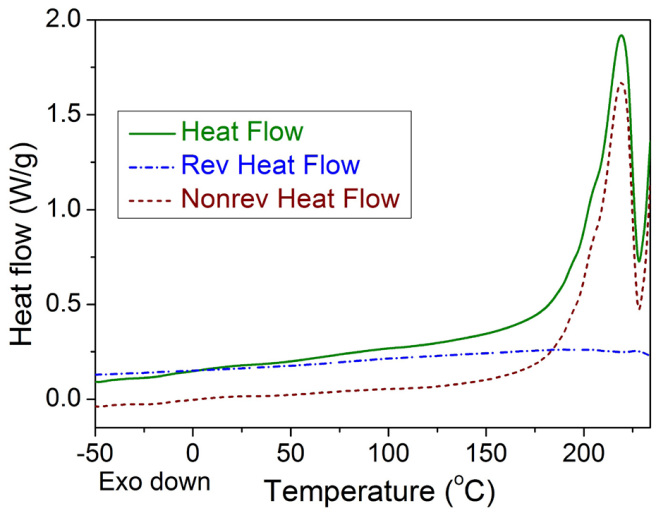

Figure 11. TMDSC thermogram of PG.

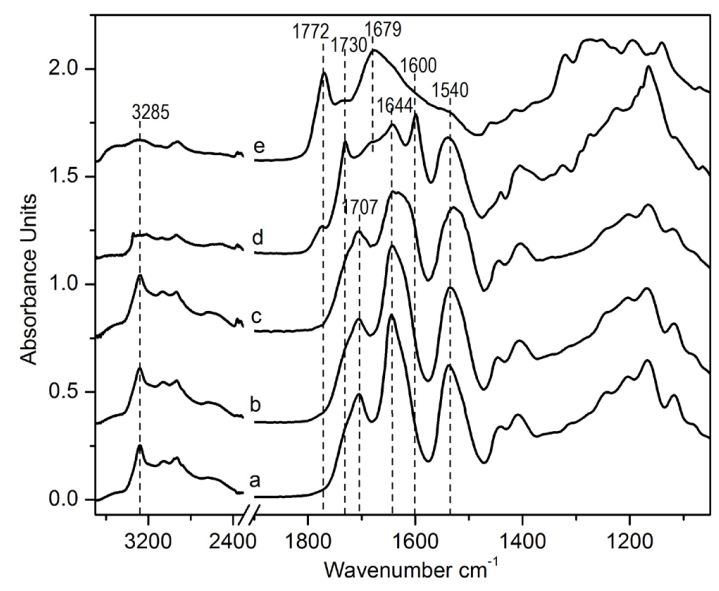

Figure 12. FT-IR spectra of PG before (a) and after heating at $185^{\circ} \mathrm{C}$ for $1.5 \mathrm{~h} \mathrm{(b)}$; and after heating to $220^{\circ} \mathrm{C}$ (c), (d) $250{ }^{\circ} \mathrm{C}$ and $300{ }^{\circ} \mathrm{C}$ (e). The curves are shifted vertically for clarity. nonrev. heat flow curve and no transition is found in the rev. heat flow. This transition is attributed to the melting of PG, which is immediately followed by degradation of PG. This was further confirmed by the FT-IR analysis of PG as a function of heating temperature. As shown in Figure 12, the IR result indicated that the structure of $\mathrm{PG}$ was maintained below $220^{\circ} \mathrm{C}$. Above $220^{\circ} \mathrm{C}$, the decrease in intensity of the $\mathrm{C}=\mathrm{O}$ absorption band at $1707-1710 \mathrm{~cm}^{-1}$ accompanied by the appearance of new absorption bands at 1772 and $1730 \mathrm{~cm}^{-1}$, which could be ascribed to the vibration frequencies of an imide group, indicates thermolysis of PG. Further heating to above $300{ }^{\circ} \mathrm{C}$ could result in carbonization of the polymer.

\subsection{Characterization of $P G / M W C N T$ composites}

Composites of MWCNTs and PG matrix were fabricated by mixing $\mathrm{PG}$ with nanotubes in chloroform, followed by solvent evaporation afterward. The dispersion of MWCNTs in chloroform was conducted under ultrasonication. From the morphological observation by TEM (Figure 13), it was observed that at CNT contents below $2 \mathrm{wt} \%$, the CNTs were mostly dis-entangled and dispersed relatively homogeneously in the matrix. At CNT content of $2 \mathrm{wt} \%$, randomly dispersed entangled clusters of CNT aggregates existed. Further increasing CNT content to $3 \mathrm{wt} \%$ led to nonuniform distribution of entangled CNT bundles. Therefore, $1 \mathrm{wt} \%$ CNT loading was optimal.

The XRD pattern of the PG/MWCNT composite of $1 \mathrm{wt} \%$ CNT loading is compared with that of PG in Figure $9 \mathrm{~b}$. In addition to characteristic diffraction peaks attributed to the structure of $\alpha$-helical PG, the MWCNT/PG composite showed a characteristic diffraction peak at $\mathrm{q}=18.3 \mathrm{~nm}^{-1}$ $(\mathrm{d}=0.34 \mathrm{~nm})$, which can be assigned to the diffracted pattern peak (002) of $\mathrm{CNTs}^{42-44}$. Similar reflection peaks attributed to the PG phase were observed for both PG and the PG/MWCNT composite, indicating that the addition of CNTs did not affect the conformation of PG.
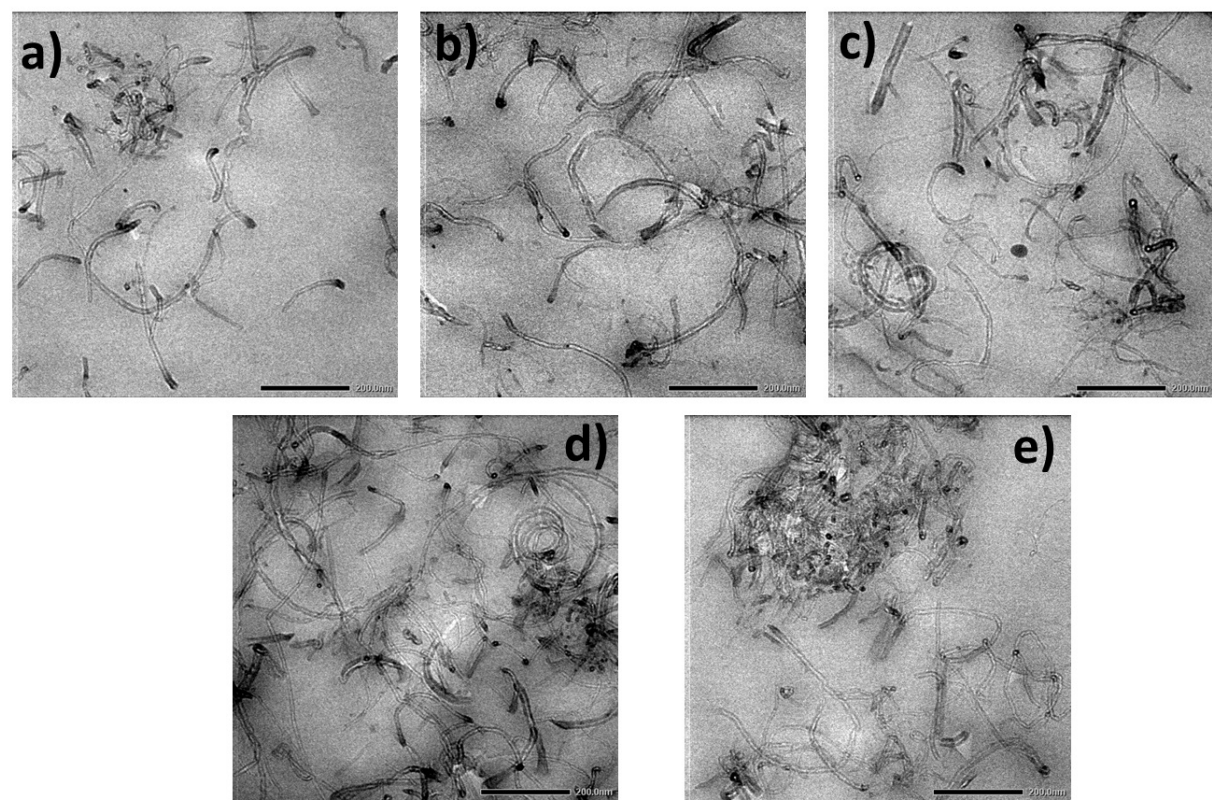

Figure 13. TEM micrographs of MWCNT/PG composites with CNT contents of 0.5 (a), 0.75 (b), 1.0 (c), 1.5 (d) and 2.0 (e) wt\%. 
Table 1. Mechanical properties of MWCNT/PG composites.

\begin{tabular}{ccc}
\hline $\begin{array}{c}\text { CNT loading } \\
\text { (wt\%) }\end{array}$ & $\begin{array}{c}\text { Tensile strength } \\
\text { (MPa) }\end{array}$ & $\begin{array}{c}\text { Strain at break } \\
(\mathbf{\%})\end{array}$ \\
\hline 0 & $14.7 \pm 2.1$ & $31.5 \pm 4.1$ \\
\hline 0.5 & $16.4 \pm 2.2$ & $37.4 \pm 4.0$ \\
\hline 0.75 & $17.5 \pm 1.9$ & $40.1 \pm 5.5$ \\
\hline 1.0 & $19.7 \pm 2.0$ & $34.7 \pm 4.7$ \\
\hline 1.5 & $17.6 \pm 2.4$ & $29.6 \pm 5.4$ \\
\hline 2.0 & $14.3 \pm 2.3$ & $29.4 \pm 5.2$ \\
\hline
\end{tabular}

The mechanical properties of MWCNT/PG composites with different MWCNT contents are summarized in Table 1. The tensile strength of the composites increased with increasing CNT content from 0 to $1.0 \mathrm{wt} \%$ and then slightly decreased. The CNTs have a positive effect on tensile strength as a result of their stiffness and high aspect ratio as well as good dispersion in the PG matrix. Apparently, the secondary structure of proteins and polypeptides in general has a significant effect on their interactions with CNT's surface ${ }^{45}$. It has also been reported that the diameter/ curvature of CNTs could be sensed by $\alpha$-helical peptides, resulting in reciprocal interactions ${ }^{46}$. Thus, both the rod-like structure and helix macrodipole of PG may play a key role on the spatial orientation and interactions with MWCNTs, which was likely contributed by several interface forces like hydrophobic, charge $-\pi$ and van der Waals interactions ${ }^{47,48}$.

The slight decrease in tensile strength for the CNT loadings above $1.0 \mathrm{wt} \%$ could be attributed to aggregation of the CNTs. Accordingly, the strain at break slightly increased with the MWCNT content upto $0.75 \mathrm{wt} \%$ due to the positive effect of the added reinforcement on the material toughness. However, higher MWCNT contents lowered the composite ductility as a good balance between a high content and a good dispersity of MWCNTs was not obtained.

It has been reported that nanocomposites of microbial polyglutamic acid and nanoclays showed an enhancement of the tensile strenth by approximately $30-40 \%$ with $3 \mathrm{wt} \%$ of compatibilized nanoclays, and even up to ca. $500 \%$ with $70 \mathrm{wt} \%$ of nanoclay content ${ }^{19}$. Therefore, such a moderate increase by ca. $34 \%$ of the tensile strength of the composite upon adding $1 \mathrm{wt} \%$ of MWCNT (from $14.7 \pm 2.1$ to $19.7 \pm 2.0 \mathrm{MPa}$ ) is attributed to the quite low MWCNT content incorporated. Nevertheless, this result provides the basis for future investigation of a proper surfactant as a compatibilizer between the PG matrix and MWCNT in order to enhance the incorporable MWCNT content.

\section{Conclusions}

In conclusion, $\alpha$-helical poly(L-glutamic acid) was suscessfully obtained via catalytic hydrogenation of poly(benzyl glutamate). The reaction conditions, including the catalyst content, temperature, time and hydrogen pressure were investigated to achieve a complete reduction process. The advantage of this method is that the obtained PG exhibited in an $\alpha$-helix structrure. It was further demonstrated that the efficient dispersion of MWCNTs in the $\alpha$-helical PG matrix was feasible, resulting in MWCNT/PG biocomposites. The results pave the pathway for future research to enhance the incorporable MWCNT content and the composite performance, making the material potential in biomedical applications such as tissue engineering.

\section{Acknowledgements}

This research is funded by Vietnam National University HoChiMinh City (VNU-HCM) under grant number NV201920a-01/HĐ-KHCN.

\section{References}

1. Ashiuchi M, Nawa C, Kamei T, Song J-J, Hong S-P, Sung $\mathrm{M}-\mathrm{H}$, et al. Physiological and biochemical characteristics of poly $\gamma$-glutamate synthetase complex of Bacillus subtilis. Eur J Biochem. 2001;268(20):5321-8.

2. Ulery BD, Nair LS, Laurencin CT. Biomedical applications of biodegradable polymers. J Polym Sci, B, Polym Phys. 2011;49(12):832-64.

3. Shih I-L, Van Y-T. The production of poly-( $\gamma$-glutamic acid) from microorganisms and its various applications. Bioresour Technol. 2001;79(3):207-25.

4. Li C. Poly(1-glutamic acid)-anticancer drug conjugates. Adv Drug Deliv Rev. 2002;54(5):695-713.

5. Papadimitriou SA, Achilias DS, Bikiaris DN. Chitosan-g-PEG nanoparticles ionically crosslinked with poly(glutamic acid) and tripolyphosphate as protein delivery systems. Int J Pharm. 2012;430(1-2):318-27.

6. Cao B, Yin J, Yan S, Cui L, Chen X, Xie Y. Porous scaffolds based on cross-linking of poly(l-glutamic acid). Macromol Biosci. 2011;11(3):427-34.

7. Luo Z, Guo Y, Liu J, Qiu H, Zhao M, Zou W, et al. Microbial synthesis of poly- $\gamma$-glutamic acid: current progress, challenges, and future perspectives. Biotechnol Biofuels. 2016;9(1):134.

8. Hanby WE, Waley SG, Watson J. 632. Synthetic polypeptides. Part II. Polyglutamic acid. J Chem Soc. 1950;3239-49.

9. Nguyen L-TT, Vorenkamp EJ, Daumont CJM, Brinke G, Schouten AJ. Double-brush Langmuir-Blodgett monolayers of $\alpha$-helical diblock copolypeptides. Polymer. 2010;51(5):1042-55.

10. Shih IL, Van YT, Shen MH. Biomedical applications of chemically and microbiologically synthesized poly(glutamic acid) and poly(lysine). Mini Rev Med Chem. 2004;4(2):179-88.

11. Nguyen L-TT, Ardana A, ten Brinke G, Schouten AJ. Surface Potentials in langmuir monolayers of unidirectionally oriented $\alpha$-helical diblock copolypeptides. Langmuir. 2010;26(9):651521.

12. Segura-Sánchez F, Montembault V, Fontaine L, Martínez-Barbosa ME, Bouchemal K, Ponchel G. Synthesis and characterization of functionalized poly( $\gamma$-benzyl-1-glutamate) derivates and corresponding nanoparticles preparation and characterization. Int J Pharm. 2010;387(1-2):244-52.

13. Williams FD, Brown RD. The rate of $\gamma$-benzyl-L-glutamate NCA polymerizations. Biopolymers. 1973;12(3):647-54.

14. Caron A, Bunel C, Braud C, Vert M. Pd/charcoal-catalysed cleavage of benzyl ester protecting groups in poly(benzyl acrylate) and poly(benzyl methacrylate). Polymer. 1991;32(14):2659-65.

15. Caron A, Braud C, Bunel C, Vert M. Blocky structure of copolymers obtained by $\mathrm{Pd} / \mathrm{C}$-catalysed hydrogenolysis of benzyl protecting groups as shown by sequence-selective hydrolytic degradation in poly $(\beta$-malic acid $)$ derivatives. Polymer. 1990;31(9):1797-802.

16. Katchalski E, Grossfeld I, Frankel M. Poly-lysine. J Am Chem Soc. 1947;69(10):2564-5.

17. Gamarra A, Martínez de Ilarduya A, Vives M, Morató J, Muñoz-Guerra S. Ionic complexes of poly( $\gamma$-glutamic acid) with alkyltrimethylphosphonium surfactants. Polymer. 2017;116:4354. 
18. Antunes JC, Pereira CL, Molinos M, Ferreira-da-Silva F, Dessì M, Gloria A, et al. Layer-by-layer self-assembly of chitosan and poly $(\gamma$-glutamic acid) into polyelectrolyte complexes. Biomacromolecules. 2011;12(12):4183-95.

19. Gamarra A, Muñoz-Guerra S, Urpí L, Galbis E, Galbis JA. Nanocomposites of microbial polyglutamic acid and nanoclays compatibilized by organophosphonium surfactants. Macromol Chem Phys. 2018;219(12):1800083.

20. Mittal G, Dhand V, Rhee KY, Park S-J, Lee WR. A review on carbon nanotubes and graphene as fillers in reinforced polymer nanocomposites. J Ind Eng Chem. 2015;21:11-25.

21. Zeng Y, Ci L, Carey BJ, Vajtai R, Ajayan PM. Design and reinforcement: vertically aligned carbon nanotube-based sandwich composites. ACS Nano. 2010;4(11):6798-804.

22. Shin SR, Bae H, Cha JM, Mun JY, Chen Y-C, Tekin H, et al. Carbon nanotube reinforced hybrid microgels as scaffold materials for cell encapsulation. ACS Nano. 2012;6(1):362-72.

23. Yang N, Chen X, Ren T, Zhang P, Yang D. Carbon nanotube based biosensors. Sens Actuators B Chem. 2015;207:690-715.

24. Sheikholeslam M, Wheeler SD, Duke KG, Marsden M, Pritzker $\mathrm{M}, \mathrm{Chen}$ P. Peptide and peptide-carbon nanotube hydrogels as scaffolds for tissue \& 3D tumor engineering. Acta Biomater. 2018;69:107-19.

25. Mo Y, Brahmachari S, Lei J, Gilead S, Tang Y, Gazit E, et al. The inhibitory effect of hydroxylated carbon nanotubes on the aggregation of human islet amyloid polypeptide revealed by a combined computational and experimental study. ACS Chem Neurosci. 2018;9(11):2741-52.

26. El-Mahdy AFM, Kuo S-W. Diphenylpyrenylamine-functionalized polypeptides: secondary structures, aggregation-induced emission, and carbon nanotube dispersibility. RSC Advances. 2018;8(28):15266-81.

27. El-Mahdy AFM, Kuo S-W. A pyrene-functionalized polytyrosine exhibiting aggregation-induced emission and capable of dispersing carbon nanotubes and hydrogen bonding with P4VP. Polymer. 2018;156:10-21.

28. Bahr JL, Yang J, Kosynkin DV, Bronikowski MJ, Smalley RE, Tour JM. Functionalization of carbon nanotubes by electrochemical reduction of aryl diazonium salts: a bucky paper electrode. J Am Chem Soc. 2001;123(27):6536-42.

29. Etika KC, Jochum FD, Cox MA, Schattling P, Theato P, Grunlan JC. Tailoring properties of carbon nanotube dispersions and nanocomposites using temperature-responsive copolymers of pyrene-modified poly(N-cyclopropylacrylamide). Macromolecules. 2010;43(22):9447-53.

30. Cornille F, Copier J-L, Senet J-P, Robin Y. Procédé de Préparation des N-carboxyanhydrides. Eur. Pat. Appl. 1201659. 2002.

31. Daly WH, Poché D. The preparation of N-carboxyanhydrides of $\alpha$-amino acids using bis(trichloromethyl)carbonate. Tetrahedron Lett. 1988;29(46):5859-62.

32. Vayaboury W, Giani O, Cottet H, Deratani A, Schué F. Living polymerization of $\alpha$-amino acid $\mathrm{N}$-carboxyanhydrides (NCA) upon decreasing the reaction temperature. Macromol Rapid Commun. 2004;25(13):1221-4.
33. Nguyen L-TT, Ardana A, Vorenkamp EJ, ten Brinke G, Schouten AJ. Chain length dependence of the helix orientation in LangmuirBlodgett monolayers of $\alpha$-helical diblock copolypeptides. Soft Matter. 2010;6(12):2774-85

34. Derr JB, Tamayo J, Espinoza EM, Clark JA, Vullev VI. Dipoleinduced effects on charge transfer and charge transport. Why do molecular electrets matter? Can J Chem. 2018;96(9):843-58.

35. Bonduelle C. Secondary structures of synthetic polypeptide polymers. Polym Chem. 2018;9(13):1517-29.

36. Li H, Shi L-Y, Cui W, Lei W-W, Zhang Y-L, Diao Y-F, et al. Covalent modification of graphene as a 2D nanofiller for enhanced mechanical performance of poly(glutamate) hybrid gels. RSC Advances. 2015;5(105):86407-13.

37. Papadopoulos P, Floudas G, Klok HA, Schnell I, Pakula T. Self-assembly and dynamics of poly $(\gamma$-benzyl-1-glutamate $)$ peptides. Biomacromolecules. 2004;5(1):81-91.

38. Schmidt A, Lehmann S, Georgelin M, Katana G, Mathauer K, Kremer F, et al. Molecular Dynamics of "Hairy Rod" Molecules in the Solid State: Poly(.gamma.-methyl L-glutamate)-co-(. gamma.-n-octadecyl L-glutamate) in Solution-Cast Films. Macromolecules. 1995;28(16):5487-97.

39. Wilkes GL. Unique highly developed superstructure in films of poly $(\gamma$-benzyl-L-glutamate) cast in a magnetic field. J Polym Sci B. 1972;10(12):935-40.

40. Wilkes GL, Mohadger Y, Holaday W. Structural studies of single spherulites and partially spherulitic films of poly(methyl-D-glutamate). J Polym Sci, Polym Phys Ed. 1976;14(2):251-62.

41. Reading M, Luget A, Wilson R. Modulated differential scanning calorimetry. Thermochim Acta. 1994;238:295-307.

42. Wardle BL, Saito DS, García EJ, Hart AJ, de Villoria RG, Verploegen EA. Fabrication and characterization of ultrahighvolume- fraction aligned carbon nanotube-polymer composites. Adv Mater. 2008;20(14):2707-14.

43. Che BD, Nguyen BQ, Nguyen L-TT, Nguyen HT, Nguyen VQ, Van Le T, et al. The impact of different multi-walled carbon nanotubes on the $\mathrm{X}$-band microwave absorption of their epoxy nanocomposites. Chem Cent J. 2015;9(1):10.

44. Saleh TA, Gupta VK. Photo-catalyzed degradation of hazardous dye methyl orange by use of a composite catalyst consisting of multi-walled carbon nanotubes and titanium dioxide. J Colloid Interface Sci. 2012;371(1):101-6.

45. Zhou X, Su J, Wang C, Fang C, He X, Lei W, et al. Design, preparation and measurement of protein/CNTs hybrids: A concise review. J Mater Sci Technol. 2020;46:74-87.

46. Jeong W, Choi S, Choi JS, Lim Y. Chameleon-like self-assembling peptides for adaptable biorecognition nanohybrids. ACS Nano. 2013;7(8):6850-7.

47. Chen RJ, Zhang Y, Wang D, Dai H. Noncovalent sidewall functionalization of single-walled carbon nanotubes for protein immobilization. J Am Chem Soc. 2001;123(16):3838-9.

48. Calvaresi M, Zerbetto F. The devil and holy water: protein and carbon nanotube hybrids. Acc Chem Res. 2013;46(11):245463. 